\title{
Ecological model of competitive interaction among three species of amphipods associated to Bryocladia thrysigera (J. Agardh) and extreme environmental stress effects
}

\author{
Máurea Nicoletti Flynn and William Roberto Luiz Silva Pereira
}

(MNF) Professor Orientador do Curso de Pós-Graduação em Tecnologia para o Ambiente, Faculdade de Tecnologia Unicamp, Campus Limeira, R. Dr. Barachisio Lisboa 105 casa 2 - São Paulo - SP, 05441-090. E-mail: maureaflynn@gmail.com

(WRLSP) Assessor Técnico Bio.Sensu Consultoria Ecológica, R. Gabriel Alves, 211 - Jd. Miriam - São Paulo - SP, 04419-030. E-mail: william_roberto_luiz@hotmail.com

\begin{abstract}
Population rates of the three dominant amphipod species (Hyale nigra, Caprella danileviskii and Caprella penantis) associated to Bryocladia thrysigera, were calculated revealing similar values for the intrinsic growth rate. The empirical data modeled presented a good fit to the May-Leonard three-species competition model in a discrete Ricker form with periodic cycles for the carrying capacity. In adjusting model to data, a new method to calculate competition coefficients emerged in good agreement with ecological and behavior particularities. A simulation of environmental stochasticity was achieved by the insertion of random parameters for the calculation of each species carrying capacity. $H$. nigra presented a persistent behavior in extreme environmental stress, whereas $C$. penantis is highly sensitive to stress.
\end{abstract}

Key words: Amphipoda, Environmental Stress and Stochasticity, Population Dynamics, Three-Species Competition Model

\section{INTRODUCTION}

The partitioning of ecological phenomena in four hierarchical levels (individuals, populations, communities and ecosystems) favor ecological studies. For each hierarchical levels specific rules and forms (Lawton, 1999) such as allometric exponents and scaling laws (Marquet et al., 2005) are applicable.

At population level, Turchin (2001) proposed three laws (exponential growth, resources limitation and consumer-resource oscillations) applicable to modeling natural populations or experimental biological events. These laws have been explored by Flynn and Pereira (2011) for potential application in ecotoxicology.
Any given population has the natural ability to grow (following the exponential law) and achieve stability (through resources limitation and resource-consumer oscillation laws). However different forces derived from intrinsic and extrinsic events may affect a population modifying its behavior. As postulated by Lawton (1999), organisms are limited by their environment. In controlled experiments and for a few natural populations, these laws are clearly observed, however for many natural populations a pattern is not easily detected. Turchin (2001) discussed trophic related biological forces acting on exponential growth and resource limitation laws, besides known contingency rules 
defining environmental participation on species dynamics. Both may interfere in natural population dynamics.

Amphipods composition associated to the red alga Bryocladia trysigera (J. Agardh) F.Schmitz, 1901 from the intertidal region of Itanhaém beach in Peruíbe, São Paulo, is dominated by the species Hyale nigra (Haswell, 1979), Caprella penantis Leach, 1814 and Caprella danileviskii Czerniavski, 1861, presenting clear alternation of the numerical dominance throughout the year. Valério-Berardo and Flynn (2002) suggested that numerical fluctuation of dominant species indicates an attempt to distinguish ecological niche by means of reproductive strategies such as life cycles, incubation periods and fecundity. Attempts to explain this temporal pattern ended in failure when data on physical-chemical elements (e.g., salinity, water temperature, etc.) were used as independent variables.

This paper aims to propose a model describing the population dynamics of three dominant species of amphipods associated to Bryocladia thrysigera and to simulate dynamic scenarios of environmental stress based on previously published empirical data by Valério-Berardo and Flynn $(2002,2004)$ and Flynn et al. (2009).

\section{Material And Methods}

Based on data sampled by Valério-Berardo and Flynn (2002), natural population rates of the three dominant species (Hyale nigra, Caprella danileviskii and Caprella penantis) were calculated.

For $H$. nigra, $r_{1}$ (intrinsic rate of natural growth, also called Malthusian or Darwinian fitness) was calculated by the construction of monthly life tables where a non density-dependent value was obtained (Flynn et al., 2009). The $r$ variability, associated to reproductive strategies, provides different growth rates in order to adapt to stressful conditions (intertidal region), and was here considered as regulated by environmental randomness. Valério-Berardo observed for
C.danileviskii and C.penantis a sigmoid growth (unpublished data), adjusted here, for monthly data densities, to the Pearl-Verhulst equation. This adjustment provided the parameters $r_{2}, K_{2}$ for $C$. danileviskii and $r_{3}, K_{3}$ for C.penantis.

Every population has the ability to increase in an exponential way $\left(N_{t+1}=N_{t} e^{r t}\right)$ but no natural population increases ad infinitum. There are forces controlling the population explosive growth by resources limitation summarized in the carrying capacity $(K)$ parameter and incorporated to the Pearl-Verhulst equation, or its analog form, the Ricker discrete equation (Royama, 1992):

$$
N_{t+1}=N_{t} \exp \left[r\left(1-\frac{N_{t}}{K}\right)\right]
$$

In a natural community, taxonomically close species share similar resources and compete for them. The competitive interference is summarized as the $\alpha_{12}$ parameter which affects the carrying capacity and is modeled as:

$$
N_{t+1}=N_{t} \exp \left[r\left(1-\frac{N_{t}+\alpha_{12} N_{2}}{K}\right)\right]=N_{t} \exp \left[r\left(\frac{K-N_{t}-\alpha_{12} N_{2}}{K}\right)\right]
$$

Community can be modeled in what is known as the Ricker type competition model for $\mathrm{n}$ competing species (Roeger, 2005):

$$
\begin{gathered}
N_{i, t+1}=N_{i, t} \exp \left[r_{i}\left(1-\frac{N_{i, t}+\sum_{j=1}^{n} \alpha_{i j} N_{j, t}}{K}\right)\right] \\
\text { When reducing the number of }
\end{gathered}
$$
competitors to three species, the discrete May-Leonard competition model is applied.

$$
\begin{aligned}
& N_{1, t+1}=N_{1, t} \exp \left[r_{1}\left(1-\frac{N_{1, t}+\alpha_{12} N_{2, t}+\alpha_{13} N_{3, t}}{K_{1}}\right)\right] \\
& N_{2, t+1}=N_{2, t} \exp \left[r_{2}\left(1-\frac{N_{2, t}+\alpha_{21} N_{1, t}+\alpha_{23} N_{3, t}}{K_{2}}\right)\right] \\
& N_{3, t+1}=N_{3, t} \exp \left[r_{3}\left(1-\frac{N_{3, t}+\alpha_{31} N_{1, t}+\alpha_{32} N_{2, t}}{K_{3}}\right)\right]
\end{aligned}
$$

Where the coefficients $\alpha_{12}, \alpha_{13}, \alpha_{21}$, $\alpha_{23}, \alpha_{31}, \alpha_{32}\left(\alpha_{i j}\right)$ represent the competitive interference of species $j$ on species $i$.

Assuming that the carrying capacity $(K)$ fluctuates cyclically (Gotelli, 2001), the cosine term does support the generation of periodic cycles of frequency $c_{i}$. The term $k_{i}$ determines the cycle amplitude.

$$
K_{i, t}=K_{i, t}+k_{i}\left[\cos \left(\frac{2 \pi t}{c_{i}}\right)\right]
$$


The cosine term for the first equation was replaced by the term sin (inverse of cosine) as $H$. nigra carrying capacity varies in opposite direction from that of the two other species (Valério-Berardo and Flynn, 2002) (see Fig. 1).

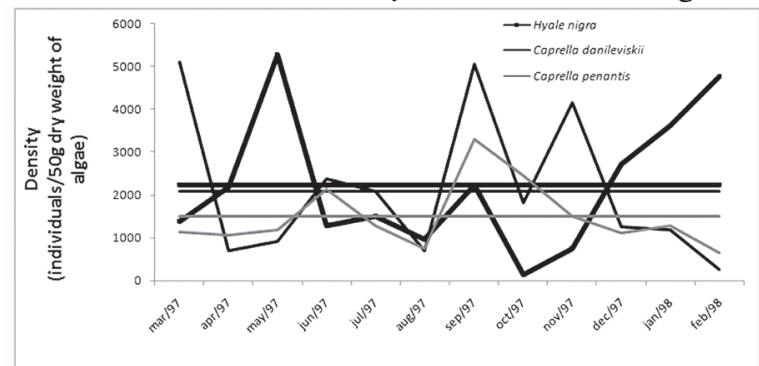

Figure 1. H. nigra, C. danileviskii and C. penantis temporal fluctuations (March 1997 to February 1998). Horizontal lines represent average density of each species considered.

The system is capable of generating periodic cycles for the carrying capacity while preserving each population intrinsic parameters. Nevertheless, the modeled cycles did not represent faithfully the time series empirical pattern, probably because of "noises" interferences from the natural system, both abiotic and biotic, that should be considered. These sources of variability can be synthesized and incorporated into the model through a term $\varepsilon$ drawn from random numbers between 0 and 1 , which varies as a function of time, $\varepsilon_{t}$, and acts directly on the carrying capacity. Thus the final model becomes:

$$
\begin{aligned}
& N_{1, t+1}=N_{1, t} \exp \left[r_{1}\left(1-\frac{N_{1, t}+\alpha_{12} N_{2, t}+\alpha_{13} N_{3, t}}{\left\{K_{1, t}+k_{1}\left[\operatorname{sen}\left(\frac{2 \pi t}{c_{i}}\right)\right]\right\} \varepsilon_{1, t}}\right)\right] \\
& N_{2, t+1}=N_{2, t} \exp \left[r_{2}\left(1-\frac{N_{2, t}+\alpha_{21} N_{1, t}+\alpha_{23} N_{3, t}}{\left\{K_{2, t}+k_{2}\left[\cos \left(\frac{2 \pi t}{c_{2}}\right)\right]\right\} \varepsilon_{2, t}}\right)\right] \\
& N_{3, t+1}=N_{3, t} \exp \left[r_{3}\left(1-\frac{N_{3, t}+\alpha_{31} N_{1, t}+\alpha_{32} N_{2, t}}{\left\{K_{3, t}+k_{3}\left[\cos \left(\frac{2 \pi t}{c_{3}}\right)\right]\right\} \varepsilon_{3, t}}\right)\right]
\end{aligned}
$$

To produce $\varepsilon_{t}$, random drawings between 0 and 1 were taken considering four different scenarios: scenario 1 with $\varepsilon_{t}=$ 1 (without noise), scenario 2 with $0.6<\varepsilon<1$, scenario 3 with $0.2<\varepsilon_{t}<1$; scenario 4 with 0 $<\varepsilon_{t}<1$. For each scenario, a starter population of a couple $\left(N_{0}=2\right)$ was considered. For each species an independent random drawn was performed and values map identified. Time series considered has a length of 1080 days (three years).
The parameters $c_{i}$ (cycle frequency) and $k_{i}$ (cycle amplitude) were considered based on the biennial cycle verified by Valério-Berardo and Flynn (2002), imposing a 180 days cycle adaptation with alternating dominance. Amplitudes were considered by the average density of each population (data from Valério-Berardo and Flynn, 2002). Population peaks were recorded and the ratio (mean population/population peak) calculated and then applied to the adjusted theoretical carrying capacity values.

To calculate the competitive coefficients, growth rates $\left(r_{1}, r_{2}, r_{3}\right)$ and oscillating parameters $\left(c_{1}, c_{2}, c_{3}\right.$ and $\left.k_{1}, k_{2}, k_{3}\right)$ were used. For carrying capacities assessment $\left(K_{1} K_{2}\right.$, $K_{3}$ ) the population peaks values found by Valério-Berardo and Flynn (2002) were used. Modeling results, however, did not reflect the pattern presented by the actual data. To rectify this, an average curve was inserted for each theoretical population in order to adjust each curve to empirical data. Whenever theoretical population means coincided with empirical ones and theoretical population peaks with natural population peaks, the resulting values of competition coefficients and carrying capacities were recorded.

\section{RESULTS}

For $H$. nigra, empirical average density was $2238 \mathrm{ind} / 50 \mathrm{~g}$ algae, for C. danileviskii, 2136 ind $/ 50 \mathrm{~g}$ algae and for C. penantis, 1493 ind $/ 50 \mathrm{~g}$ algae. When applying correlation analysis to paired populations densities, there was a positive correlation for $C$. penantis and $C$. danileviskii $(+0.570)$, and negative correlation for $H$. nigra and $C$. danileviskii $(-0.433)$ and $H$. nigra and $C$. penantis (-0.351), showing alternating dominance between Hyale and the two Caprella species, with coincidental oscillation, as pointed out by Valério-Berardo and Flynn (2002). Temporal series of each of the species considered is shown in Figure 1. Average density was higher for $H$. nigra, followed by $C$. danileviskii and $C$. penantis.

The revealed population parameters $r_{1}$, $K_{1}, r_{2}, K_{2}, r_{3}, K_{3}$ can be checked in Figure 2 . 
Growth rates for each of the three populations considered were similar. The carrying capacity value presented by $C$. danileviskii was below and by $C$. penantis well above those found by Valério-Berardo and Flynn (2002).

Although the average intrinsic growth rate of $H$. nigra calculated by Flynn et al. (2009) is $r_{1}=0.138 /$ generation, to feed the model $r_{1}=0.05 /$ day was used. This can be explained in four different ways: in three species competition models intrinsic increase rate is usually the same for all species considered (May and Leonard, 1975; Roeger, 2005; Leach and Miritz, 2006); considering the scaling law (Fenchel, 1974) relating body size to population increase rate $\left(r_{\max } \propto M^{-0,25}\right)$, populations with similar body size present similar increase rates; similar taxonomic species have similar life histories; and, finally, the adjustment to Pearl-Verhulst equation of $H$. nigra data resulted in the expected value $r_{1}$ $=0.05 /$ day (Fig. 2).

Competition interference of Caprella species on $H$. nigra was high: $\alpha_{12}=\alpha_{13}=1.20$. And hence competition interference of $H$. nigra on each species of Caprella was low: $\alpha_{21}=0.26$ and $\alpha_{31}=0.21$ (Table 1). The model showed that $C$. penantis exerts a strong competitive force on $C$. danileviskii $\left(\alpha_{23}=0.90\right)$, and $C$. danileviskii affects less intensely $C$. penantis $\left(\alpha_{32}=0.21\right)$.

When starting simulation with initial population densities, each population quickly enters into an oscillatory pattern respecting dominance alternation. Population peaks, as well as average densities, remained close to those found for natural populations (Fig. 3). Despite the "noise" in empirical series and the asymmetrical biannual cycle, the model retains the three species dynamics main features.

Four scenarios of competition involving the three amphipod species were considered (Fig. 4).

The straight model (Fig. 4A), with no "noise" addition (random variable) does not reflect external interventions, biotic or abiotic, and clearly, $H$. nigra is dominant when the densities of $C$. penantis and $C$. danileviskii are low and vice versa.
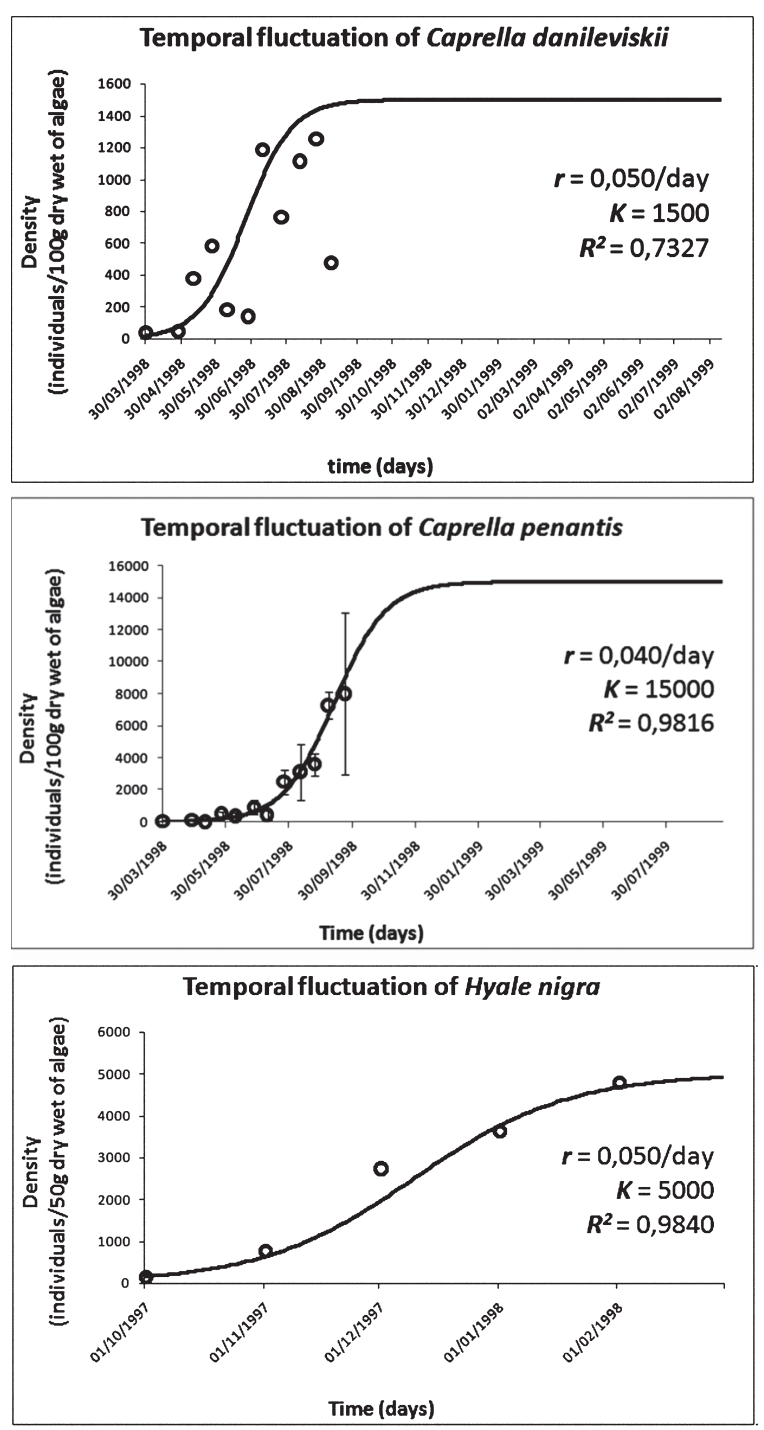

Figure 2. Sigmoid growth for $C$.danileviskii, $C$. penantis and $H$. nigra. The first two species were sampled from 30/03/1998 to $22 / 09 / 1998$. Data for $C$. penantis consists of three samples taken biweekly; deviations are represented on the chart by bars. For $C$. danileviskii each point represents one sample. All individuals, male, female and young, were considered. The adjustment of the logistic curve revealed $r_{2}=0.050 /$ day, $\mathrm{K}_{2}=1500$ and $\mathrm{r}_{3}=0.040 /$ day, $\mathrm{K}_{3}=15000$. The population parameters of $H$. nigra were calculated for October 1997 to February 1998 from data published by Valério-Berardo and Flynn (2002).

Table 1. Parameters used on and disclosed by the competition model. Note that carrying capacities were higher than the population peaks assessed by Valério-Berardo and Flynn (2002).

\begin{tabular}{ccccccc}
\hline \multicolumn{2}{c}{ Hyale nigra } & \multicolumn{2}{c}{ Caprella danileviskii } & \multicolumn{2}{c}{ Caprella penantis } \\
\hline Parameters & Model & Parameters & Model & Parameters & Model \\
$r_{1}$ & 0.500 & $r_{2}$ & 0.500 & $r_{3}$ & 0.500 \\
$K_{1}$ & 9000 & $K_{2}$ & 5400 & $K_{3}$ & 3600 \\
\hline$\alpha_{12}$ & 1.20 & $\alpha_{21}$ & 0.26 & $\alpha_{31}$ & 0.21 \\
$\alpha_{13}$ & 1.20 & $\alpha_{23}$ & 0.90 & $\alpha_{32}$ & 0.21 \\
\hline$k_{1}$ & $78 \%$ in $K_{1}$ & $k_{2}$ & $77 \%$ in $K_{2}$ & $k_{3}$ & $83 \%$ in $K_{3}$ \\
$c_{1}$ & $360 / 2$ & $c_{2}$ & $360 / 2$ & $c_{3}$ & $360 / 2$ \\
\hline
\end{tabular}



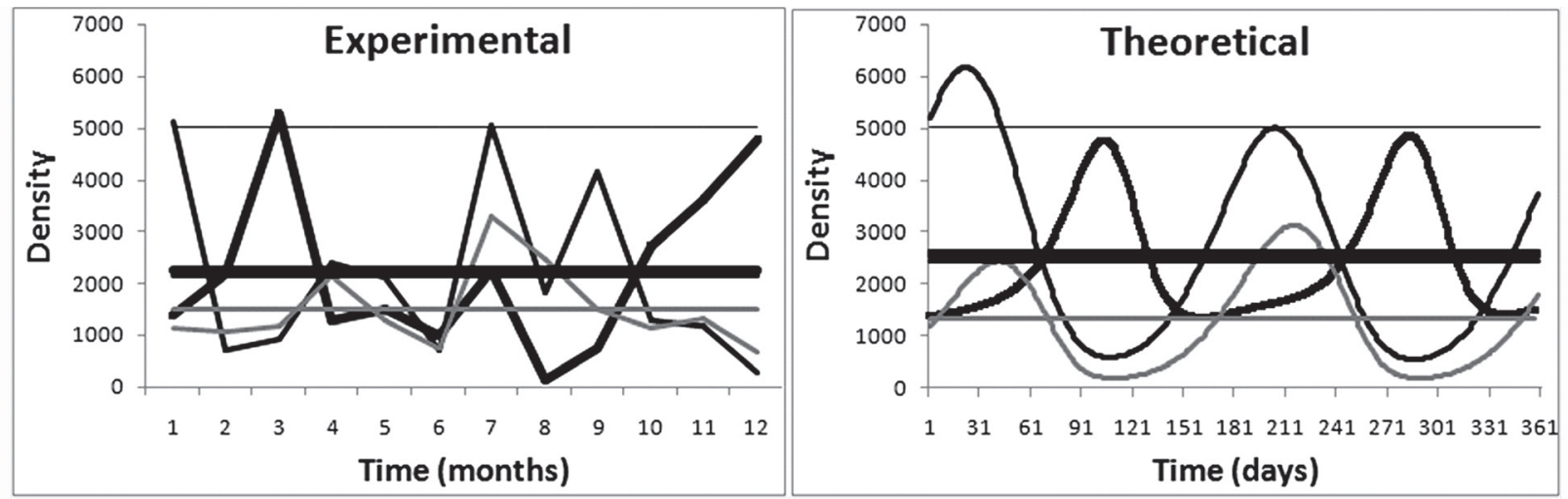

Figure 3. Values generated by modeling experimental (empirical) versus theoretical data.

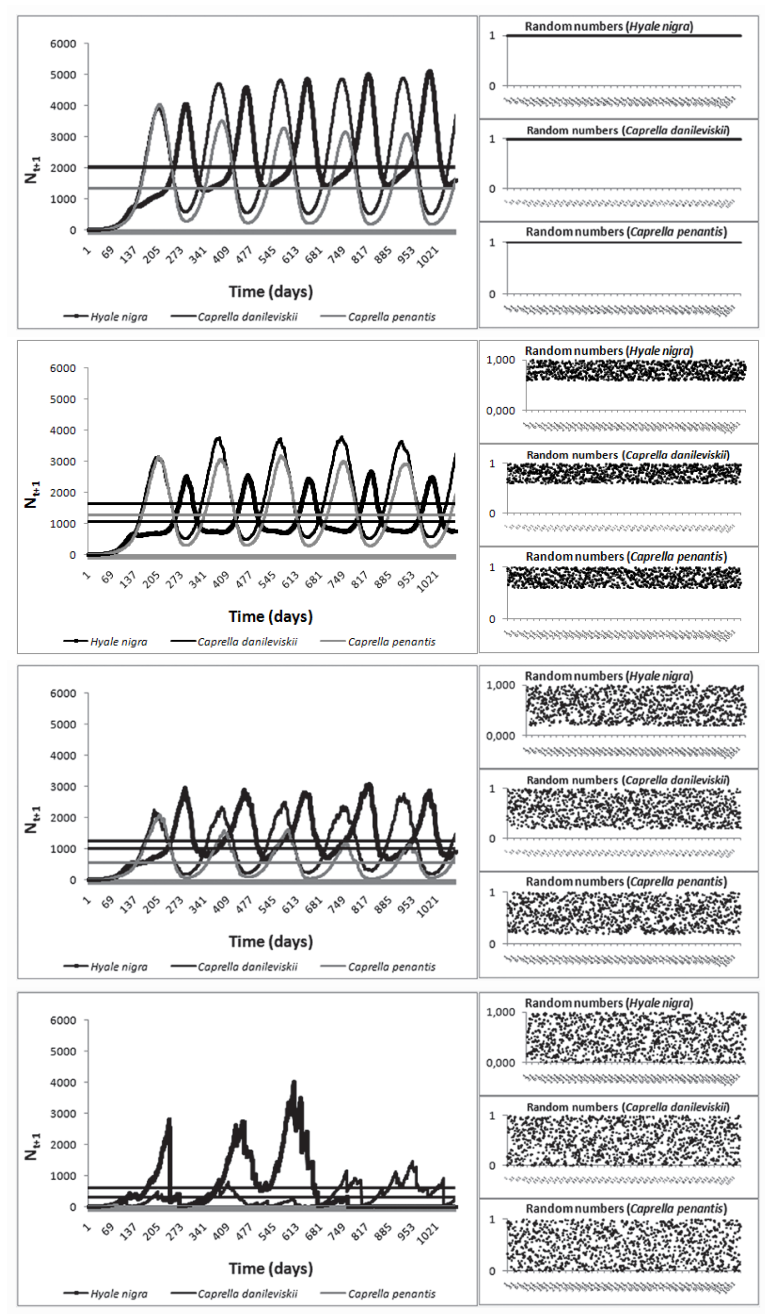

Figure 4. Four scenarios of competition as three amphipods species were considered. 4A) Straight model, no interference of random variable; $4 \mathrm{~B}$ ) Insertion of random variable numbers drawn between 0.6 and 1.0 ; 4 C) Insertion of random variable (0.2 and 1.0$)$; 4D) Insertion of the random variable $(0$ and 1.0). Along with each graphic, the random numbers distribution for each drawn is shown.

The system dynamics characteristics were maintained when inserting random variable numbers drawn between 0.6 and 1.0 (Fig. 4B) or 0.2 and 1.0 (Fig. 4C). In such cases, random variables never generated values $\varepsilon_{t}=0$ and therefore there was no extinction. The only visible effect of environmental randomness is a decrease in average mean densities as "noise" increases.

When modeling an extremely noisy environment, insertion of random variables drawn between 0 and 1.0 (Fig. 4D), each of the three populations disappears and reappears, disrespecting the cyclical behavior built into the system. The average densities are lower as the interference of environmental variables increases.

Along with each graphics (Fig. 4), the random numbers distribution for each drawn is shown. The random number generator used does not guarantee purely random numbers [Hurst exponent $\mathrm{H}=1 / 2$ (Mandelbrot, 1982)].

\section{Discussion}

It is highly desirable that ecological models are robust enough to predict the abundance of a given population in the future, helping the decision process by effectively signaling environmental stress (Van Straalen, 2003). Interference combinations in natural systems are endless and, according to Lawton (1999), endless natural population dynamics must be acknowledged.

Oscillatory fluctuations are not exclusive to trophic interactions models and experiments. Three species competitive interactions models also generate oscillatory behavior (May and Leonard, 1975; Leach and Miritz, 2006). These models however are simplified by generalization of competition 
coefficient to facilitate mathematical analysis reducing biological significance.

Regarding the proposed model, some considerations are due: population parameters were empirical, enhancing its representation; values generated for each species intrinsic growth rate were similar enough to allow for ecological laws verification; carrying capacity values were above empirical population peaks permitting the fit to empirical data. The model revealed $K$ value of 9000 for $H$. nigra contrasting with the empirical $K$ value of 5000 for a natural population (Flynn et al., 2009). It must be observed that theoretically the carrying capacity is known only if a population is kept isolated in the system.

There are several methods to calculate competition coefficient. The most common is by the MacArthur-Levins equation (Krebs, 1999), transforming the proportion of use by two species of a given resource in competitive coefficient. Despite the debate on the actual suitability and lack of symmetry of the coefficient (Pianka, 1974; Krebs, 1999), its applicability in the current context seems justified considering that the interference of species $i$ on species $j$ is not the same as the inverse, interference of species $j$ on species $i$, which guarantees the asymmetry and simultaneously allows the description of resource distribution and niche overlap.

Resources usually considered are food or space (Krebs, 1999). Since food is not considered as limiting factor for epiphyte herbivorous species, space must be elected. As epiphytic macroalgae commonly grows faster than host macroalgal (Bravin and Yoneshigue-Valentin, 2002) mesograzers such as amphipods play a role in epibiosis control and in shaping the landscape by a top-down control upon host and epiphytic algae (Jabocucci et al., 2008).

Caprella penantis and $C$. danileviskii have the ability of attaching more firmly to the substrate due to the use of gnathopod 1 in a "parallel" posture rather than in the "upright" posture used by species living in calmer waters
(Guerra-García et al., 2002). When comparing the morphological structures of the two species of Caprella and $H$. nigra, it seems that both Caprella have a selective advantage for an algae substrate life, explaining partially the high interference values of both species on $H$. nigra.

Environmental interferences were calculated independently for each species since its effects can be felt by each population differently (physiologically, for instance). In a noisy environment, where conditions are not stable (i.e. low constancy in physical parameters, high biological interference and increased pollution stress), populations are unable to stabilize, the dominance alternation found in the natural system does not occur, and species with low carrying capacity are excluded.

Running the model several times, $H$. nigra tended to reach higher densities and along with $C$. danileviskii persisted for longer periods than $C$. penantis. The limited persistence of $C$. penantis can be explained by low carrying capacity.

Although intrinsic growth rates for the three species are virtually identical, in noisy environments $H$. nigra persists for a longer period and reaches higher peak densities than C. penantis and $C$. danileviskii, even suffering intense competitive interference from both. Growth rate does not establish $H$. nigra as an opportunist species, its numerical dominance and persistence may be partially explained by the species high mobility, efficient use of space, herbivorous behavior, and ability to colonize unstable (noisy) environment (Flynn et al., 2009). All mentioned characteristics expressed on its high carrying capacity value.

The applied model predicts that species will exert alternating dominance and retain their natural characteristics in most circumstances. It is also able to identify how different stress forces will affect system dynamics by lowering the species carrying capacity till, in extreme cases, null values (when $N_{t+1}=0$ and the species becomes extinct in the system). 
ACKNOWLEDGMENTS - We are grateful to Maria Teresa Valério-Berardo in yield data and to the contribution of anonymous reviewers.

\section{REFERENCES}

Bravin, I.C. and Yoneshigue-Valentin, Y. 2002. Influência de fatores ambientais sobre o crescimento in vitro de Hypnea musciformis (Wulfen) Lamouroux (Rhodophyta). Revista Brasileira de Botânica, 25(4):469-474.

Fenchel, T. 1974. Intrinsic rate of natural increase: the relationship with body size. Oecologia, 14: 317-326.

Flynn, M.N.; Pereira, W.R.L.S.; Pires, R.C. and ValérioBerardo, M.T. 2009. Population dynamics of Hyalenigra(Haswell, 1879) (Amphipoda, Hyalidae) Associated to Bryocladia thrysigera (J. Agardh) at Peruíbe beach, Itanhaém (SP), southeastern Brazil. Nauplius, 17(1): 1-8.

Flynn, M.N. and Pereira, W.R.L.S. 2011. Population-based approach in ecotoxicology. Revinter, 4: 79-81.

Gotelli, N.J. 2001. A Primer of Ecology.3rd Edition.Sinauer Associates, Sunderland, Mass. 265pp.

Guerra-García, J.M.; Corzo, J. and Gómez-García, J.C. 2002. Clinging behaviour of the Caprellidea (Amphipoda) from the Strait of Gibraltar. Crustaceana, 75(1): 41-50.

Jacobucci, G.B.; Güth, A.Z. and Leite, F.P.P. 2008. Experimental evaluation of amphipod grazing over biomass of Sargassum filipendula (Phaeophyta) and its dominant epiphyte. Nauplius, 16(2): 65-71.

Krebs, C.J. 1999. Ecological methodology. Addison Wesley Longman, Menlo Park, California, 620pp.

Lawton, J.H. 1999. Are there General Laws in ecology? Oikos, 84: 177-192.

Leach P.G.L and Miritzis, J. 2006. Analytic behavior of competition among three species. Journal of Mathematical Nonlinear Physics, 13(4): 535-548.

Mandelbrot, B.B. 1982. The fractal geometry of Nature. W.H. Freeman and Company, New York.

Marquet, P.A.; Quinones, R.A.; Abbots, S.; Labra, F.; Tognellim M.; Arim, M. and Rivadeneira, M. 2005. Scaling and power-laws in ecological systems. Journal of Experimental Biology, 208: 1749-1769.

May, R.M. and Leonard, W.J. 1975. Nonlinear aspects of competition between three species. SIAM Journal on Applied Mathematics, 29: 243-253.

Pianka, E.R. 1974. Niche overlap and diffuse competition. Proceedings of the National Academy of Science of the U.S.A. 71: 2141-2145.

Roeger, L.I.W. 2005. Discrete May-Leonard competition models II. Discrete and Continuous Dynamical Systems Series B, 5: 841-860.

Royama, T. 1992. Analytical Population Dynamics. Chapman, Hall, London.

Turchin, P. 2001. Does Population ecology have general Laws? Oikos, 94: 17-26.

Valério-Berardo, M.T. and Flynn, M.N. 2002. Composition and seasonality of an amphipod community to the associated algae Bryocladia trysigera. Brazilian Journal of Biology, 62(4A): 735-742.

Valério-Berardo, M.T. and Flynn, M.N. 2004. Population biology of Hyale nigra (Haswell, 1879) (Amphipoda, Hyalidae) associated to Bryocladia thyrsigera (J. Agardh) at Peruibe, Itanhaém beach, southeastern Brazil. Nauplius, 12(1): 1-10.

Van Straalen, N.M. 2003. Ecotoxicology becomes stress ecology. Environmental Science and Technology, 37(17): 324A-330A. 